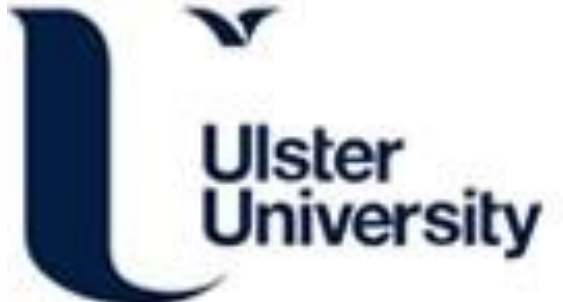

\section{Alcohol use, regular use, disorder and remission from use disorders in Northern Ireland: a prevalence study}

Bunting, B., \& Bharat, C. (2019). Alcohol use, regular use, disorder and remission from use disorders in Northern Ireland: a prevalence study. Addiction Research and Theory, 27(4), 347-353.

https://doi.org/10.1080/16066359.2018.1524881

Link to publication record in Ulster University Research Portal

Published in:

Addiction Research and Theory

Publication Status:

Published (in print/issue): 04/07/2019

DOI:

10.1080/16066359.2018.1524881

\section{Document Version}

Author Accepted version

\section{General rights}

Copyright for the publications made accessible via Ulster University's Research Portal is retained by the author(s) and / or other copyright owners and it is a condition of accessing these publications that users recognise and abide by the legal requirements associated with these rights.

\section{Take down policy}

The Research Portal is Ulster University's institutional repository that provides access to Ulster's research outputs. Every effort has been made to ensure that content in the Research Portal does not infringe any person's rights, or applicable UK laws. If you discover content in the Research Portal that you believe breaches copyright or violates any law, please contact pure-support@ulster.ac.uk. 


\title{
Alcohol use, regular use, disorder and remission from use disor- ders in Northern Ireland: a prevalence study
}

\section{Brendan Bunting ${ }^{1 *}$ AQ16 Chrianna Bharat ${ }^{2}$}

\author{
${ }^{1}$ Bamford Centre, Psychology Research Institute, Ulster University, L'Derry, Northern Ireland; \\ ${ }^{2}$ National Drug and Alcohol Research Centre, UNSW Sydney, Sydney, Australia \\ *CONTACT Brendan Bunting bp.bunting@ulster.ac.uk School of Psychology, Ulster University, Magee Campus, College Avenue, \\ L'Derry BT48 7J L, Northern Ireland.
}

\begin{abstract}
Background: This study presents prevalence estimates and ages of onset for alcohol use, regular use, use disorders and remission from use disorders in Northern Ireland, and the time for transitioning between these stages.

Methods: Data on alcohol use, lifetime history, and remission from alcohol conditions as defined by the DSM -IV were collected using the Composite International Diagnostic Interview.

Results: By the age of 17 years $50 \%$ of the age cohort had started taking alcohol. By 19 years of age $67 \%$ of the cohort were regular users, and by 20 years of age $45 \%$ of the cohort were abusing alcohol. Remission from abuse/ dependence was related to the number of years since commencing the use of alcohol, with women being more likely than men to move to remission sooner, and the cohort in which the person had commenced alcohol consumption also influenced the move to remission.

Conclusions: The consumption of alcohol is high within Northern Ireland with some $83 \%$ of the population consuming alcohol, and with over $90 \%$ of this group taking alcohol on a regular basis. The abuse of alcohol was particularly marked amongst students and males, with dependence showing a higher prevalence amongst those with the lowest level of educational attainment, and where the commencement of alcohol consumption was at an early age. Transitions between stages of lifetime alcohol use, regular use, and use disorders were associated with the early commencement of alcohol use, education, cohort use and being male.
\end{abstract}

KEYWORDS alcohol use; use disorder; remission; prevalence; Northern Ireland

\section{FUNDING}

Australian National Health and M edical Research Council (NHM RC), 10.13039/501100000925, 1081984

Data collection was funded by the HSC Research and Development Division, Public Health Agency, Northern Ireland. The data cleaning was done as part of the World M ental Health Survey Consortium and funded through a variety of grants www.hcp.med.harvard.edu/wmh/. This work was also supported by an Australian National Health and M edical Research Council (NHM RC) project grant [no. 1081984]. AQ15

\section{Introduction}

In 1975 23\% of males and 50\% of females living in Northern Ireland were life-long abstainers from alcohol; an overall population figure representing 37\% of the reported estimated population (Blaney and McKenzie 1980: data collection took place in 1975). There can be little doubt that these figures have substantially changed during the past 40 years. Of course, such a comparison relates to cross-sectional data from two points in time and does little to elucidate the nature of this change. This paper is an examination of the current situation with regards to the consumption of alcohol. What is the current prevalence rate, and at what age do the majority start to drink alcohol? In addition, the paper also examines the transitions between stages of lifetime alcohol use, regular use, and use disorders and the factors that can influence these trajectories.

Deaths in Northern Ireland from cirrhosis of the liver are the second highest in the UK, and at an area level indicate a strong social gradient with a rate of 7.6 per 100,000 of the population occurring in the least deprived quintile, and a rate of 27 per 100,000 in the most deprived quintile. In terms of the UK the recorded rate of alcohol related deaths per 100,000 of the population was 30.9 in Scotland, 22.2 in Northern Ireland, 17.4 in Wales and 14.5 in England (age 
standardised adjusted). https://www.ons.gov.uk/peoplepopulationandcommunity/healthandsocialcare/causesofdeath/ bulletins/alcoholrelateddeathsintheunitedkingdom/registeredin2016. At the individual level a strong social gradient has also been reported in terms of alcohol abuse and dependence, where factors such as level of education, social context, and peer group have all been found to be related to higher levels of alcohol consumption ((Degenhardt et al. 2008, 2016).

Other key determinants and drivers to remission for alcohol commencement, abuse, and dependence have been chronological ages, historical period, birth cohort and gender (Anthony et al. 1994; Grant 1996; Holdcraft and Iacono 2002; Rice et al. 2003; Grucza et al. 2008; Slade et al. 2016). A person's age and his/her being within a given cohort group can have a substantial influence on the commencement of alcohol consumption, and hence shape the pattern of future drinking behaviour.

The current study, using epidemiological data from Northern Ireland, sets out the prevalence of alcohol consumption, abuse and level of dependence in the society, while examining the periods involved from regular use to abuse and dependence. These transitions are examined in the context of age, alcohol commencement, gender, level of education, and cohort use.

\section{Method}

\section{Sample design}

The Northern Ireland Mental Health Survey was a nationally representative sample. A multi-stage area probability sampling design was used to select respondents to the survey. Wards were selected from within each of 26 Local Government Districts on a probability proportionate to size basis. Within each selected Ward, two Census Output Areas were randomly selected, and within each of these a random sample of 10 dwellings was selected. A Kish selection strategy was used to select the person to be interviewed within each household. In total 4340 Individuals were interviewed during the course of study, and the response rate was $68.4 \%$.

Respondents were administered a modified version of the World Mental Health Surveys' Composite International Diagnostic Interview (WMH-CIDI) (Kessler and Üstün 2004). Due to the length of the instrument, the interview was often administered in two parts. All respondents in the survey were administered Part I of the interview. Part II of the interview was administered to all who endorsed any of the core diagnoses in Part I and a subsample of all other respondents. The alcohol module was included in Part II of the interview and as such, the current report utilises data from the 1,986 Part II respondents. All interviewers received standardised training and quality control was applied in a similar manner across countries (Pennell et al. 2008).

Diagnoses of abuse and dependence were derived using the WMH-CIDI diagnostic algorithms, based on the DSMIV alcohol use criteria. Each respondent was asked if they had ever consumed an alcoholic beverage, and the age at which they had first used alcohol. Subsequent questions determined if, at any point in their lifetime, respondents had consumed alcohol regularly (at least 12 standard drinks in a year) and if they had met criteria for the Diagnostic and Statistical Manual IV's definition of abuse or dependence (American Psychiatric Association. Diagnostic and Statistical Manual of Mental Disorders, IV-TR, 2000). Questions regarding alcohol use disorders were only asked of persons who, in the year they drank most, drank alcohol at least once per week or consumed three or more standard drinks on any drinking occasion. Remission from these use disorders, defined as not having experienced any disorder-related symptoms for at least 12 months prior to the interview, was also evaluated.

\section{Weights, clusters and missing data}

Individual-level weights were created on the basis of sample selection, non-responses and the poststratification factors of age, sex and geographical region, using procedures described in Heeringa et al. (2008). Clustering and stratification were based on the geographical strategy used to select the sample. All statistical results were adjusted for these survey design effects in order to maintain the representativeness of the sample.

\section{Data analysis}

Analyses were carried out using SAS version 9.4, with weighted prevalence (standard error) produced using PROC SURVEYFREQ, life-table (actuarial) estimates of the survival functions for age of onset and remission obtained using 
SAS PROC LIFETEST, and discrete-time survival models conducted in PROC SURVEYLOGISTIC using a logistic link function and person-year as the unit of analysis.

Associations of basic socio-demographics and cohort-level lifetime prevalence of alcohol use with transitions between all levels of involvement with alcohol were investigated (with the exception of remission to dependence due to insufficient number of cases). A contextual variable was created to capture the time-varying level of alcohol use among an individual's birth cohort. An individual's birth cohort was defined as all persons of the same sex born $+/-5$ years of their year of birth, resulting in 11-year wide sex-specific cohorts centred around year of birth. The variable included in the analyses was the proportion (/10) of people in the individual's birth cohort who had used alcohol by the prior person year.

Other variables considered in all transition analyses included sex and time-varying education level ((student (in continuing education), low (primary education only), medium (GCSE/O-level), and high (higher level)).

The age of commencement of alcohol use was categorised into tertiles and labelled as early (15 years or less), mid (16-18 years) or late (19 years or more), and included in all models except commencement of use. Age groupings of person-year were defined as follows; 14 years or less, 15-17, 18-20, 21-24, 25-29 and 30+ years for use and use disorder models, and 18 years or less, 19-20, 21-22, 23-24, 25-29, 30-39 and 40+ years for the remission model. Modelling the transition to remission from abuse also adjusted for the speed at which the transition from use to disorder was made and defined as either early ( $0-3$ years), mid ( $4-8$ years) or late ( $9+$ years) tertile. Coefficients were reported as odds ratios (ORs). Significance tests were evaluated using 0.05-level two-sided tests.

\section{Results}

\section{Prevalence}

Lifetime prevalence of alcohol use was $83 \%(\mathrm{se}=1.0)$ with $75 \%(\mathrm{se}=1.3)$ of respondents reporting having ever used regularly. Of the entire population, $10.7 \%(\mathrm{se}=0.9)$ had alcohol abuse (without dependence) and $2.5 \%(\mathrm{se}=0.4)$ dependence in their lifetime. Among alcohol users (conditional prevalence), regular use was very prominent at $90 \%$ (se $=1.1)$, and approximately one in six users had an alcohol use disorder $(12.9 \%(\mathrm{se}=1.1)$ abuse, $3 \%$ (se $=0.5)$ dependence), with $15.9 \%(\mathrm{se}=1.2$ ) having a use disorder. Prevalence of remission was slightly higher among cases of alcohol abuse $(79 \%(\mathrm{se}=3.4))$ compared to alcohol dependence $(70.4 \%(\mathrm{se}=7.1))$.

Based on cross-national comparisons using conditional lifetime prevalence for alcohol use, the Northern Ireland figures are at the top end of the range for having (a) regular users of alcohol and (b) individuals who have alcohol dependence (Detailed international comparison to be published in a separate paper).

\section{Age of onset}

The age of onset (AOO) for alcohol use, regular use, abuse and dependence, and remission from these disorders are shown in Figure 1; these figures include censored cases and all plot points have been scaled so that all curves eventually reach $100 \%$. Over $50 \%$ of persons who eventually used alcohol did so by the age of 17 . The minimum legal age of drinking alcohol in the UK is 18 years. By 19 years, two-thirds (67\%) of lifetime regular users had already used regularly. By the age of 20, $45 \%$ of persons who abused alcohol had done so, along with some $26 \%$ of dependence cases. By the early 30 s, over $45 \%$ of those who had abused alcohol were in remission; comparably, by the same time, only $15 \%$ of those who were dependent on alcohol had remitted.

Figure 1. Age of onset curves for alcohol use, regular use, use disorders and remission; includes censored cases with all data points scaled such that all curves reach $100 \%$. 


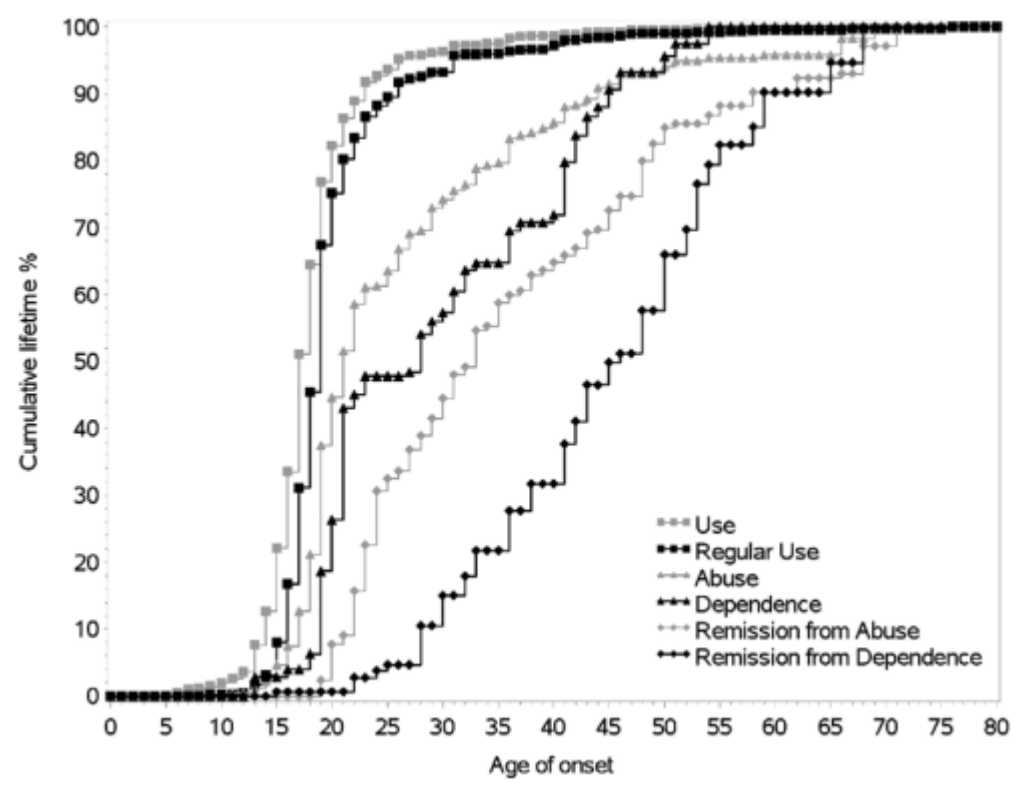

\section{Time between transitions}

Figure 2 shows the cumulative curves for the transition time between stages of alcohol involvement. The time from first alcohol use to commencing regular use was by far the fastest transition, with over $60 \%$ of the sample who made this transition doing so within 2 years. Fifty percent of those who transitioned from use of alcohol to abuse did so within a period of six years, with $75 \%$ of this group having made this transition within 12 years. The transition out of abuse was similarly timed, with half the eventual remission from abuse cases reaching this stage within five years from onset of disorder.

Figure 2. Cumulative time to transition curves for all transitions considered; each curve includes only those persons that reached the second stage.

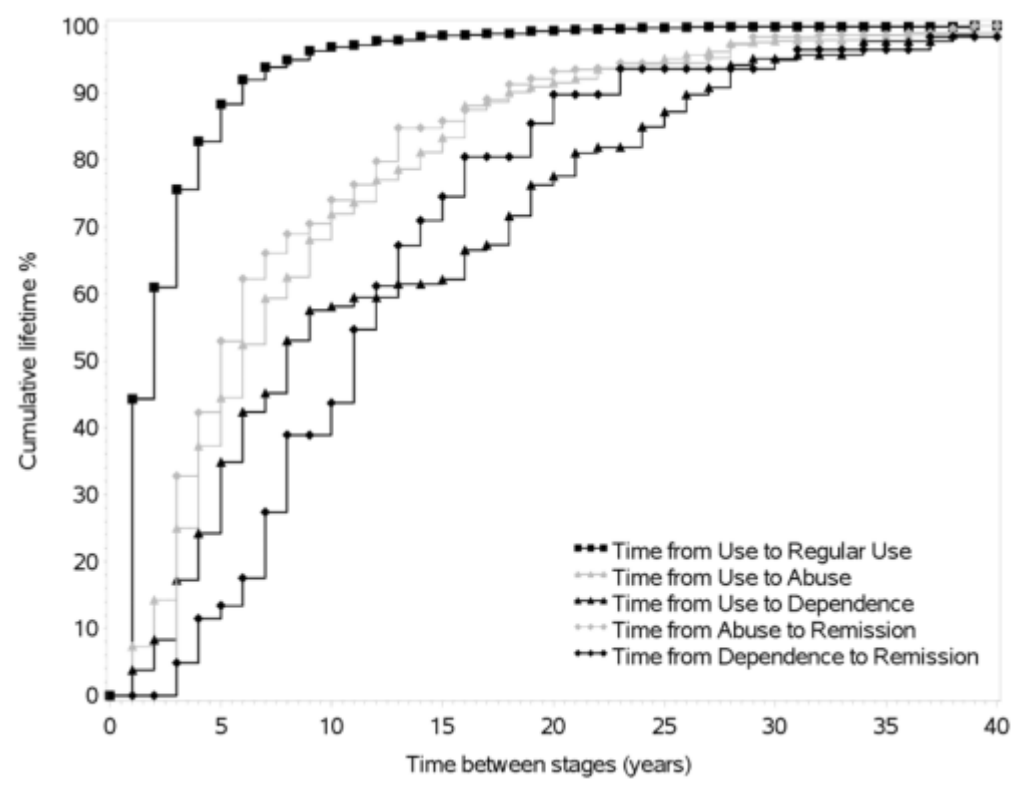


Transitions from alcohol consumption to alcohol dependence took on average eight years before 50\% of this subpopulation had made this transition, and 18 years before $75 \%$ of those who made this transition from alcohol consumption to dependency had occurred. Among remission from dependence cases, transitions from the disorder were initially slow, with it taking 11 years before $50 \%$ of this group were in remission. The remission rate then quickly increased, taking only another four years (total transition time of 15 years from onset of disorder) for an additional $25 \%$ of eventual remission cases to transition out of dependence.

\section{Modelling transitions through stages of alcohol involvement}

Table 2 displays the results of modelling transitions from (1) abstinence to commencement of alcohol use; transitions from use to (2) regular use of alcohol, (3) abuse of alcohol, and (4) dependence on alcohol; and transitions from regular use to (5) abuse and (6) dependence on alcohol. Gender was significantly associated with all transitions, with the exception of commencing use; from both use and regular use, men had greater than twice the odds of transitioning to either abuse or dependence compared to females (OR ranging from 2.15-2.61). Once using alcohol, the age (in tertiles) at which the person first used alcohol was a factor of importance for all stages of alcohol consumption.

Table 2. Multivariate associations of socio-demographic variables with transitions between stages of lifetime alcohol use, regular use and use disorders. Table Layout

\begin{tabular}{|c|c|c|c|c|c|c|c|c|c|c|c|}
\hline \multirow[t]{2}{*}{ Variable } & \multirow[t]{2}{*}{ Category } & \multicolumn{2}{|c|}{ Commencing Use ${ }^{\mathrm{a}}$} & \multicolumn{2}{|c|}{ Use to regular use } & \multicolumn{2}{|c|}{$\begin{array}{l}\text { Use to abuse (with- } \\
\text { out prior depend- } \\
\text { ence) }\end{array}$} & \multicolumn{2}{|c|}{ Use to dependence } & \multicolumn{2}{|c|}{$\begin{array}{l}\text { Regular use to abuse } \\
\text { (without prior de- } \\
\text { pendence) }\end{array}$} \\
\hline & & OR & $95 \% \mathrm{CI}$ & OR & $95 \% \mathrm{CI}$ & OR & $95 \% \mathrm{CI}$ & OR & $95 \%$ CI & OR & $95 \% \mathrm{CI}$ \\
\hline \multirow{2}{*}{$\begin{array}{l}\text { Gender (Ref: } \\
\text { Female) }\end{array}$} & Male & 1.06 & $(0.93-1.22)$ & $1.42 *$ & $(1.15-1.76)$ & $2.61 *$ & $(2.00-3.40)$ & $2.34 *$ & $(1.28-4.29)$ & $2.34 *$ & $(1.79-3.05)$ \\
\hline & $X^{2}{ }_{1}[p]$ & 0.79 & {$[0.374]$} & $10.36 * *$ & {$[0.001]$} & $50.34 * *$ & {$[<0.001]$} & $7.54 * *$ & {$[0.006]$} & $38.77 * *$ & {$[<0.001]$} \\
\hline \multirow[t]{2}{*}{ Context $^{b}$} & $\begin{array}{l}\text { Cohort } \\
\text { use }\end{array}$ & $1.43 *$ & $(1.35-1.51)$ & $1.14 *$ & $(1.08-1.21)$ & $1.37 *$ & $(1.21-1.55)$ & 1.14 & $(0.86-1.50)$ & $1.28 *$ & $(1.12-1.46)$ \\
\hline & $X^{2}{ }_{1}[p]$ & $158.94 * *$ & {$[<0.001]$} & $20.53 * *$ & {$[<0.001]$} & $24.59 * *$ & {$[<0.001]$} & 0.79 & {$[0.375]$} & $12.73 * *$ & {$[<0.001]$} \\
\hline \multirow{5}{*}{$\begin{array}{l}\text { Education } \\
\text { level (Ref: } \\
\text { High) }\end{array}$} & Student & 1.17 & $(0.70-1.97)$ & $1.94 *$ & $(1.09-3.46)$ & $2.63 *$ & $(1.18-5.91)$ & 0.9 & $(0.30-2.67)$ & $2.71 *$ & $(1.21-6.10)$ \\
\hline & Low & 0.93 & $(0.53-1.62)$ & $1.99 *$ & $(1.20-3.29)$ & 1.41 & $(0.59-3.40)$ & 2.12 & $(0.46-9.73)$ & 1.32 & $(0.53-3.29)$ \\
\hline & $\begin{array}{l}\text { Low- } \\
\text { average }\end{array}$ & 0.99 & $(0.58-1.71)$ & $1.96 *$ & $(1.06-3.65)$ & 1.13 & $(0.56-2.27)$ & 1.70 & $(0.66-4.38)$ & 1.04 & $(0.51-2.10)$ \\
\hline & $\begin{array}{l}\text { High- } \\
\text { average }\end{array}$ & 0.78 & $(0.46-1.32)$ & 1.43 & $(0.84-2.44)$ & 1.00 & $(0.63-1.59)$ & 0.93 & $(0.37-2.34)$ & 1.01 & $(0.64-1.59)$ \\
\hline & $X_{4}^{2}[p]$ & $15.33 * *$ & {$[0.004]$} & $13.84 * *$ & {$[0.008]$} & $10.31 * *$ & {$[0.035]$} & 2.5 & {$[0.646]$} & $10.39 * *$ & {$[0.034]$} \\
\hline
\end{tabular}

OR - odds ratios; CI - confidence interval; */** Significant at the 0.05 level, two-sided test.

All discrete-time analyses here control for person-year age groups of $<=15,16-17,18-20,21-24,25-29$ and $30+($ Ref).

a Age tertile of commencing alcohol use was included in all models except transition to initial use.

${ }^{\mathrm{b}}$ Percentage (/10) of $+/-5$-yr sex-specific cohort who had used alcohol by the prior person year. e.g. For a female born in 1975 the coh born between 1970 and 1980. A context OR of 1.5 in commencement of use would be interpreted as an increase of $50 \%$ in the odds with a $10 \%$ increase of people in the age-sex cohort having commenced use by the previous person year (controlling for all other val

'Individuals' age of commencing alcohol use is split into tertiles among all those who ever used alcohol. The earliest (first) tertile is tertile age $16-18$ and the 3 rd tertile aged $19+$.

${ }^{\mathrm{d}} \mathrm{N}=$ The total unweighted number of respondents included in model conditioning on initial stage.

Respondents were excluded from the modelling of the transition if they never met criteria for the initial stage, or if the onset of the the onset of the second stage. 


\begin{tabular}{|c|c|c|c|c|c|c|c|c|c|c|c|c|}
\hline \multirow[t]{2}{*}{ Variable } & \multirow[t]{2}{*}{ Category } & \multicolumn{2}{|c|}{ Commencing Use $\mathrm{e}^{\mathrm{a}}$} & \multicolumn{2}{|c|}{ Use to regular use } & \multicolumn{2}{|c|}{$\begin{array}{l}\text { Use to abuse (with- } \\
\text { out prior depend- } \\
\text { ence) }\end{array}$} & \multicolumn{2}{|c|}{ Use to dependence } & \multicolumn{2}{|c|}{$\begin{array}{l}\text { Regular use to abuse } \\
\text { (without prior de- }^{\text {pendence) }}\end{array}$} & $\operatorname{Re}_{;}$ \\
\hline & & OR & $95 \%$ CI & OR & $95 \%$ CI & OR & $95 \%$ CI & OR & $95 \%$ CI & OR & $95 \% \mathrm{CI}$ & $\mathrm{OI}$ \\
\hline \multirow{3}{*}{$\begin{array}{l}\text { Age tertile of } \\
\text { commencing } \\
\text { alcohol use } \\
\text { (Ref: Late) }\end{array}$} & Early & & & $0.44 *$ & $(0.31-0.64)$ & \multicolumn{2}{|c|}{$1.66(0.89-3.08)$} & \multicolumn{2}{|c|}{$6.51 *(2.35-18.04)$} & \multicolumn{2}{|c|}{$1.34(0.71-2.52)$} & \\
\hline & Mid & & & $0.59 *$ & $(0.45-0.78)$ & \multicolumn{2}{|c|}{$0.74(0.38-1.45)$} & $2.93 *$ & $(1.01-8.57)$ & \multicolumn{2}{|c|}{$0.67(0.34-1.31)$} & \\
\hline & $X^{2} 2[p]$ & & & $19.22 * *$ & {$[<0.001]$} & $16.78 * *$ & {$[<0.001]$} & $14.90 * *$ & {$[0.001]$} & $11.58 * *$ & {$[0.003]$} & \\
\hline Sample Size & $\begin{array}{l}\text { Total } \\
\left(N^{d}\right)\end{array}$ & & & & 1669 & & 669 & & 1669 & & 1493 & \\
\hline \multicolumn{13}{|c|}{ OR - odds ratios; CI - confidence interval; */** Significant at the 0.05 level, two-sided test. } \\
\hline \multicolumn{13}{|c|}{ All discrete-time analyses here control for person-year age groups of $<=15,16-17,18-20,21-24,25-29$ and $30+($ Ref $)$. } \\
\hline \multicolumn{13}{|c|}{ a Age tertile of commencing alcohol use was included in all models except transition to initial use. } \\
\hline \multicolumn{13}{|c|}{$\begin{array}{l}\text { 'Individuals' age of commencing alcohol use is split into tertiles among all those who ever used alcohol. The earliest (first) tertile is age } \\
\text { tertile age } 16-18 \text { and the } 3 \text { rd tertile aged } 19+.\end{array}$} \\
\hline \multicolumn{13}{|c|}{${ }^{\mathrm{d}} \mathrm{N}=$ The total unweighted number of respondents included in model conditioning on initial stage. } \\
\hline
\end{tabular}

Among those that commenced use in the early- to mid-age range (18 years or less) transitions to regular use were associated with decreased odds, while the reverse was observed for transitions from use to dependence. Education level was significantly associated with transitions to use, regular use and abuse. The odds of transitioning from use to regular use among students, and those with low (primary level), and low-average education (GCSE/O-level), were almost twice those with a high-average education (highest level) (OR ranging from 1.94-1.99). Individuals in continuing education (students) when compared with those with the highest level of education were also associated with substantially higher odds of transitioning from use to abuse, without dependence (OR 2.71,95\% CI 1.21-6.10). Dependence on alcohol was higher amongst those with the least education.

Table 3 displays the results from modelling the transition from alcohol abuse to remission from abuse. Men were less likely to remit than females (OR 0.54, 95\% CI 0.36-0.81). Increased odds were associated with a $10 \%$ increase in an individual's cohort already using alcohol (OR 1.84, 95\% CI 1.20-2.81). No significant association was found between transition to remission from abuse and level of education. 
Table 3. Multivariate associations of socio-demographic variables with transitions from alcohol abuse to remission. Table Layout

\begin{tabular}{|c|c|c|c|}
\hline \multirow[t]{2}{*}{ Variable } & \multirow[t]{2}{*}{ Category } & \multicolumn{2}{|c|}{ Abuse (without dependence) to remission from abuse } \\
\hline & & OR & $95 \% \mathrm{CI}$ \\
\hline \multirow[t]{2}{*}{ Gender (Ref: Female) } & Male & $0.54 *$ & $(0.36-0.81)$ \\
\hline & $X^{2}{ }_{1}[p]$ & $9.13 * *$ & {$[0.003]$} \\
\hline \multirow[t]{2}{*}{ Context $^{\mathrm{a}}$} & Cohort use & $1.84 *$ & $(1.20-2.81)$ \\
\hline & $X_{1}^{2}[p]$ & $7.77 * *$ & {$[0.005]$} \\
\hline \multirow[t]{5}{*}{ Education level (Ref: High) } & Student & 0.97 & $(0.18-5.22)$ \\
\hline & Low & 1.04 & $(0.48-2.24)$ \\
\hline & Low-average & 0.77 & $(0.28-2.15)$ \\
\hline & High-average & 0.87 & $(0.54-1.39)$ \\
\hline & $X_{4}^{2}[p]$ & 0.54 & {$[0.970]$} \\
\hline \multirow{3}{*}{$\begin{array}{l}\text { Age tertile of commencing al- } \\
\text { cohol use }^{\text {b }} \text { (Ref: Late) }\end{array}$} & Early & $1.63 *$ & $(1.01-2.64)$ \\
\hline & Mid & 0.68 & $(0.46-1.00)$ \\
\hline & $X_{2}^{2}[p]$ & $16.33 * *$ & {$[<0.001]$} \\
\hline \multirow{3}{*}{$\begin{array}{l}\text { Speed to transition from use to } \\
\text { disorderc (Ref: Late) }\end{array}$} & Early & $1.71 *$ & $(1.10-2.66)$ \\
\hline & Mid & 0.99 & $(0.48-2.06)$ \\
\hline & $X_{2}^{2}[p]$ & $9.96 * *$ & {$[0.007]$} \\
\hline \multirow[t]{2}{*}{ Time with disorder } & Years & $0.96 *$ & $(0.93-0.99)$ \\
\hline & $X^{2}{ }_{2}[p]$ & $7.36 * *$ & {$[0.007]$} \\
\hline Sample size & Total $\left(\mathrm{N}^{\mathrm{d}}\right)$ & & 190 \\
\hline \multicolumn{4}{|c|}{ OR - odds ratios; CI - confidence interval; */** Significant at the 0.05 level, two-sided test. } \\
\hline \multicolumn{4}{|c|}{$\begin{array}{l}\text { Discrete time logistic regression analysis controls for person-year age groups of }<=18,19-20,21-22,23-24,25-29 \text {, } \\
30-39 \text { and } 40+(\text { Ref). }\end{array}$} \\
\hline \multicolumn{4}{|c|}{$\begin{array}{l}\text { a Percentage (/10) of }+/-5-y r \text { sex-specific cohort who had used alcohol by the prior person year. e.g. For a female born } \\
\text { in } 1975 \text { the cohort would be females born between } 1970 \text { and } 1980 \text {. A context OR of } 1.5 \text { in commencement of use would } \\
\text { be interpreted as an increase of } 50 \% \text { in the odds of commencing use with a } 10 \% \text { increase of people in the age-sex cohort } \\
\text { having commenced use by the previous person year (controlling for all other variables in the model). }\end{array}$} \\
\hline \multicolumn{4}{|c|}{$\begin{array}{l}\text { ' } \text { Individuals' age of commencing alcohol use is split into survey-specific tertiles among all those who ever used alcohol. } \\
\text { The earliest (first) tertile is age }<=15 \text {, the } 2 \text { nd tertile age } 16-18 \text { and the 3rd tertile aged } 19+\text {. }\end{array}$} \\
\hline \multicolumn{4}{|c|}{$\begin{array}{l}\text { 'Individuals' speed of transition from alcohol use to disorder is split into survey-specific tertiles. When predicting } \\
\text { remission from abuse, tertiles were calculated for transition from use to abuse: the fastest at } 0-3 \text { years, the middle tertile } \\
4-8 \text { years and late transitions were } 9+\text { years. }\end{array}$} \\
\hline
\end{tabular}

However, increased odds of remitting were observed among those who commenced drinking alcohol relatively early (15 years or less) compared to late (OR 1.63, 95\% CI 1.01-2.64), and who transitioned at faster speeds (3 years or less) relative to late transitioners (OR 1.71, 95\% CI 1.10-2.66). An increase in the number of years a person was affected with alcohol abuse was associated with decreased odds of transition to remission (OR 0.96, 95\% CI 0.93-0.99).

\section{Discussion}

The current study examines the prevalence and transitions from alcohol use, use disorder and remission in a nationally representative sample of respondents in Northern Ireland. This included patterns of transition from alcohol commence- 
ment to dependence and abuse within the context of age when first use of alcohol occurred, the person's educational attainment, potential cohort effects and gender.

The data reported in this study are from a cross-sectional epidemiological study of mental health, and were part of a wider international collection of studies within the World Mental Health Survey Consortium (Kessler and Üstün 2008). To date national comparisons have not been reported, and when this is done we will have a more complete understanding of how the current results sit in comparative terms. Nevertheless, a number of comparisons are possible. Blaney and McKenzie 1980 paper on prevalence, when compared with the data reported in this study, clearly indicates a substantial shift in the consumption of alcohol. In 1980 around $37 \%$ of the population abstained from the consumption of alcohol, by 2008 this number of individuals had decreased to $17 \%$.

This comparison is based on two cross-sectional studies, at two different points in time. The one advantage is that it clearly shows the strong effects of an age cohort. This is an effect which can also be seen in the current analysis, where an increase in the use of alcohol in a given cohort was found to be associated with an increase in the adjusted odds of transitioning from use to other more harmful stages. The apparent 'normality' of alcohol consumption has a strong group and cohort effect, which indicates that it is not an inevitable outcome of a particular stage in history, though strongly determined by group influences within a particular social context. In Northern Ireland this cohort effect is particularly associated with being a student; where levels of alcohol use, and regular use to abuse, were high, though dependence was more likely to occur amongst those with the lowest level of education. This evident cohort effect is not just a within society phenomenon, nor does it necessarily indicate that similar prevalence rates of alcohol use need necessarily mean the same thing in terms of patterns of consumption (World Health Organization, Unit WHOMoSA 2014).

The legal age for buying alcohol in the UK is 18 years. Within Northern Ireland $50 \%$ of the population had started taking alcohol by the age of 17 years, and with other evidence suggesting that one-third of young people will be using alcohol once or more per week by the age of 15 years (Currie et al. 2000). This does not mean that they are all committing an illegal act since young people from the age of 16 years can drink beer, wine or cider along with a meal, provided that the alcohol has been bought by an adult and that they are accompanied by an adult. However, the consumption of alcohol is a social norm for those in this age group, for by 19 years of age some $70 \%$ of this cohort will be regular users of alcohol, (drink 3+ times p/week or 3+ drinks p/day when drinking). Many of these individuals will go on to higher levels of consumption with $45 \%$ of the cohort going on to abuse alcohol by the age of 20 . By the early 30 s many who have abused alcohol will have moved to remission, though those who have become dependent will take a substantially longer period of time before going into remission.

Based on the current results it is apparent that programs aimed at a reduction of alcohol use, in line with health reduction strategies, would need to be targeted at pre-adolescents and young adolescents as $7 \%$ had first used alcohol by the age of 13 years, and by the age of 17 years over $50 \%$ of the age cohort had used alcohol with some $30 \%$ being within the category of being a regular user of alcohol.

The age at which individuals commence taking alcohol is very similar for females and males. This is a major societal change (Blaney and McKenzie 1980; Slade et al. 2016), and while males, on average, were found to be more likely to develop more harmful patterns of consumption, there would appear to be little benefit in viewing alcohol use and misuse as more of a male issue, though differences in patterns of consumption are likely to be important in terms of long term abuse and dependence. In the current study, and in related research, alcohol consumption increases dramatically during the late teenage years and into the early twenties and then declines normatively (Leon and McCambridge 2006), though this effect may be largely influenced by the legal age of consumption. This normative decline may later be influenced by family transitions in midlife (Staff et al. 2014).

In the current study students appear to be at particular risk of transitioning to both abusing alcohol and of developing a dependence on it, when compared with their peers who have achieved (completed) a higher level of education - with an associated odds ratio of over 2.5 (Table 2). Students present a group at considerable risk of developing styles of alcohol consumption that are likely to have detrimental consequences. Given the heightened risk of alcohol misuse amongst this group it is evident that targeted interventions should pay dividends. Though the potential social class difference in terms of long term dependence may also be important, given that those with the lowest levels of education were at a higher risk of developing a dependence on alcohol. 
A further crucial factor in developing a dependency on alcohol is the age at which a person begins taking alcohol. Those who commenced the drinking of alcohol at or before the age of 15 years were much more likely to go on to develop a dependency on the substance. This added great emphasis to the need for intervention programmes to commence well before the legal age for alcohol consumption, and certainly well before starting university, which for many will be seventeen years of age.

It is likely, that for many, alcohol is seen as a relatively benign substance, especially given the advertising emphasis on individual responsibility and the neutral, if not positive health benefits to be obtained, both personally and socially (Savell et al. 2015).

The messages that are used to advertise the sale of alcohol, especially those relating to benefits of its use, need to be more carefully examined. For example, the message that alcohol may have beneficial health consequences has been widely reported, though the evidence for such a claim appears to rest on the classification of 'abstainers' many of whom may well have cut down on drinking due to a variety of causes relating to alcohol (Fillmore et al. 2006; Stockwell et al. 2016).

It was evident that regular use of alcohol quickly follows on from its commencement for a substantial section of the younger population. Results from the Millennium study in Britain reported that $13.4 \%$ of 10-11 year old children had experience of alcohol (Maggs et al. 2015), and the younger the age of alcohol commencement the greater the risk of abuse and dependence, as shown in the current study. Intervention in these early years is likely to be of greater beneficial use, as the problems associated with alcohol consumption, such as abuse and dependency, are likely to occur along a relatively short continuum after the commencement of alcohol consumption.

Programmes of intervention may benefit from an emphasis on the need for harm reduction given the large number of adolescents and young people who transition within a relatively short period from the consumption of alcohol to its use on a regular basis, and who then go on to dependence on its use. For many the move from being a regular user to abuse has taken place by the legal age of alcohol consumption, with remission from this dependence taking place for the majority within 5 years of the abuse. However, where dependence occurs it will be another 10 years before remission will be in place for the majority of such individuals. A better appreciation of this predictable course of alcohol consumption may also help to demystify the perceived benefits.

Interventions, aimed at reduction in harm due to the abuse of alcohol, certainly need also to be targeted at group peer as evident in the current study, and also reported by many others (Hawkins et al. 1992; Mundt 2011; Degenhardt et al. 2016). A greater appreciation of the normative nature of the stages of alcohol consumption is required (Botvin and Griffin 2007), especially amongst those most affected. Further, the pattern of adverse events associated with alcohol consumption, from use to abuse and dependence, also indicates the importance of changing roles, health and behavioural change (Lee et al. 2009; Abdin et al. 2014), especially during the person's late teenage years and early twenties.

The data on which this research is based has the advantage that it was part of a wider international programme of mental health research, based on DSM-IV criteria, where quality control was possible. The data was obtained through the use of trained lay interviewers. Nevertheless, the data on age of onset for each stage of commencement and transitions were retrospective self-reports. Such reporting may be subject to 'forward telescoping', where events closer in time are more likely to be reported (Shillington et al. 2012; Johnson and Schultz, 2005)AQ2. This is unlikely to have affected the order of recall. Representiveness of the sample has been maintained through the use of sampling protocols, and by the use of weighting, while taking into account the effects of clustering and stratification within the sample (Heeringa et al. 2008).

\section{Conclusions}

The onset of alcohol consumption and its regular use starts for most people during their teenage years. Eighty-three percent of people in Northern Ireland are now users of alcohol, and within this group of individuals $90 \%$ are regular users, with some $13 \%$ going on to abuse the substance, and a further $3 \%$ of individuals going on to become dependent. Transitions from use to regular use occurred for many within a period of two years. The strong effects of education, age cohort, peer group, and the age at which alcohol was first consumed, were all shown to be important indicators for elevated levels of regular use, use disorders and later remission of alcohol.

\section{Disclosure statement}


No potential conflict of interest was reported by the authors.AQ3

Table 1. Lifetime and conditional prevalence for all levels of alcohol involvement.AQ14Table Layout

\begin{tabular}{|c|c|c|c|}
\hline & $N$ & $\%^{\mathrm{a}}$ & SE \\
\hline \multicolumn{4}{|l|}{ Lifetime prevalence } \\
\hline Use & 1,986 & 83.1 & 1.0 \\
\hline Regular use & 1,986 & 74.9 & 1.3 \\
\hline Abuse without dependence & 1,986 & 10.7 & 0.9 \\
\hline Dependence & 1,986 & 2.5 & 0.4 \\
\hline \multicolumn{4}{|l|}{ Conditional prevalence } \\
\hline Regular use $^{3}$ among lifetime users & 1,669 & 90.2 & 1.1 \\
\hline $\begin{array}{l}\text { Abuse without dependence among } \\
\text { lifetime users }\end{array}$ & 1669 & 12.9 & 1.1 \\
\hline Dependence among lifetime users & 1669 & 3.0 & 0.5 \\
\hline $\begin{array}{l}\text { Remission among lifetime abuse } \\
\text { without dependence cases }\end{array}$ & 208 & 79.4 & 3.4 \\
\hline Remission among dependence cases & 68 & 70.4 & 7.1 \\
\hline \multicolumn{4}{|l|}{ SE: standard error. } \\
\hline \multicolumn{4}{|c|}{$\begin{array}{l}\mathrm{N}=\text { The total unweighted number of respondents who answered alcohol use questions for lifetime prevalence, and the } \\
\text { total unweighted number of respondents in the conditional cohort for conditional prevalence. }\end{array}$} \\
\hline
\end{tabular}

\title{
Author's ORCID
}

\author{
Chrianna Bharat (D)
}

\section{References}

Abdin E, Subramaniam M, Vaingankar JA, Chong SA. 2014. The role of sociodemographic factors in the risk of transition from alcohol use to disorders and remission in Singapore. Alcohol Alcohol. 49(1):103-108.

American Psychiatric Association. 2000. Diagnostic and statistical manual of mental disorders (fourth edition - technical revision). Washington, DC: American Psychiatric Association.

Anthony JC, Warner L, Kessler R. 1994. Comparative epidemiology of dependence on tobacco, alcohol, controlled substances, and inhalants: basic findings from the National Comorbidity Survey. Exp Clinical Psychopharmacol. 2(3): 244-268.

Blaney R, McKenzie G. 1980. The prevalence of problem drinking in Northern Ireland: a population study. Int J Epidemiol. 9:159-166.

Botvin GJ, Griffin KW. 2007. School-based programmes to prevent alcohol, tobacco and other drug use. Int Rev Psychiatry. 19(6):607-615.

Currie C, Hurrelmann K, Settertobulte W, Smith R, Todd J. 2000. Health and health behaviour among young people. International report. Copenhagen: WHO Regional Office for Europe.

Degenhardt L, Glantz M, Bharat C, Peacock A, Lago L, Sampson N, Kessler RC. 2008. The impact of cohort substance use upon likelihood of transitioning through stages of alcohol and cannabis use and use disorder: findings from the Australian National Survey on Mental Health and Wellbeing Drug and Alcohol Review. Drug Alcohol Rev. 37(4):546556.

Degenhardt L, Stockings E, Patton G, Hall WD, Lynskey M. 2016. The increasing global health priority of substance use in young people. Lancet Psychiatry. 3:251-264. 
Fillmore KM, Kerr WC, Stockwell T, Chikritzhs T, Bostrom A. 2006. Moderate alcohol use and reduced mortality risk: systematic error in prospective studies. Addiction Res Theory. 14:101-132.

Grant BF. 1996. Prevalence and correlates of drug use and DSM-IV drug dependence in the United States: results of the National Longitudinal Alcohol Epidemiologic Survey. J Subst Abuse. 8(2):195-210.

Grucza RA, Bucholz KK, Rice JP, Bierut LJ. 2008. Secular trends in the lifetime prevalence of alcohol dependence in the United States: a re-evaluation. Alcohol Clin Exp Res. 32(5):763-770.

Hawkins JD, Catalano RF, Miller JY. 1992. Risk and protective factors for alcohol and other drug problems in adolescence and early adulthood: implications for substance abuse prevention. Psycholog Bull. 112(1):64.

Heeringa SG, Wells EJ, Hubbard F, et al. 2008. Sample designs and sampling procedures. In: Kessler RC, Üstün TB, editors. The WHO world mental health surveys: global perspectives on the epidemiology of mental disorders. New York: Cambridge University Press; p. 14-32.AQ4

Holdcraft LC, Iacono WG. 2002. Cohort effects on gender differences in alcohol dependence. Addiction. 97(8):10251036.

Johnson RA, Gerstein DR. 2002. Age, period, and cohort effects in marijuana and alcohol incidence: United States females and males, 1961-1990. Sub Use Misuse. 35(6-8):925-948.AQ5

Kerr WC, Greenfield TK, Bond J, Ye Y, Rehm J. 2009. Age-period-cohort modelling of alcohol volume and heavy drinking days in the US National Alcohol Surveys: divergence in younger and older adult trends. Addiction. 104(1):2737.AQ6

Kessler RC, Üstün TB. 2004. The World Mental Health (WMH) Survey Initiative Version of the World Health Organisation (WHO) Composite International Diagnostic Interview (CIDI). Int J Method Psychiatric Res. 13:93-121.

Kessler RC, Üstün TB. (eds). 2008. The WHO world mental health surveys. New York: Global perspectives of mental health surveys Cambridge University Press.

Keyes KM, Schulenberg JE, O'Malley PM, Johnston LD, Bachman JG, Li G, et al. 2011. The social norms of birth cohorts andAQ7 adolescent marijuana use in the United States, 1976-2007. Addiction. 106(10):1790-1800.AQ8

Lee S, Guo WJ, Tsang A, He YL, Huang YQ, Zhang MY, et al. (2009). Associations of cohort and socio-demographic correlates with transitions from alcohol use to disorders and remission in metropolitan China. Addiction. 104(8):13131323.AQ9

Leon DA, McCambridge J. 2006. Liver cirrhosis mortality rates in Britain from 1950 to 2002: an analysis of routine data. Lancet. 367(9504):52-56. ISSN 0140-6736 DOI: 10.1016/S0140-6736(06)67924-5

Loughrey GC, Curran PS. 1987. The pathology of civil disorder. In: Dawson AM, Besser GM, editors. Recent advances in Medicine. Edinburgh: Churchill Livingstone.AQ10

Maggs JL, Staff J, Patrick ME, Wray-Lake L, Schulenberg JE. 2015. Alcohol use at the cusp of adolescence: a prospective national birth cohort study of prevalence and risk factors. J Adolesc Health. 56(6):639-645.

Mundt MP. 2011. The impact of peer social networks on adolescent alcohol use initiation. Acad Pediat. 11(5):414-421.

Pennell BE, Mneimneh ZN, Bowers A, et al. 2008. In: Kessler RC, Üstün TB, editors. The WHO world mental health surveys: global perspectives on the epidemiology of mental disorders. New York: Cambridge University Press; p. 3357.AQ11

Rice JP, Neuman RJ, Saccone NL, Corbett J, Rochberg N, Hesselbrock V, et al. 2003. Age and birth cohort effects on rates of alcohol dependence. Alcohol Clin Exp Res. 27(1):93-99.AQ12

Savell E, Fooks G, Gilmore AB. 2015. How does the alcohol industry attempt to influence marketing regulations? A systematic review. Addiction. 111:18-32.

Shillington AM, Woodruff SI, Clapp JD, Reed MB, Lemus H. 2012. Self-reported age of onset and telescoping for cigarettes, alcohol, and marijuana: across eight years of the National Longitudinal Survey of Youth. J Child Adoles Sub Abuse. 21(4):333-348. 
Slade T, Chapman C, Swift W, Keyes K, Tonks Z, Teesson M. 2016. Birth cohort trends in the global epidemiology of alcohol use and alcohol-related harms in men and women: systematic review and metaregression. BMJ Open. 6 (10).AQ13

Staff J, Greene K, Maggs JL, Schoon I. 2014. Family transitions and changes in drinking from adolescence through midlife. Addiction. 109(2):227-236.

Stockwell T, Zhao J, Panwar S, Roemer A, Naimi T, Chikritzhs T. 2016. Do “Moderate" drinkers have reduced mortality risk? A systematic review and meta-analysis of alcohol consumption and all-cause mortality. J Stud Alcohol Drugs. 77 (2):185-198.

World Health Organization, Unit WHOMoSA. 2014. Global status report on alcohol and health, 2014: World Health Organization. 


\section{Author Queries}

Query: AQ1: Please review the table of contributors below and confirm that the first and last names are structured correctly and that the authors are listed in the correct order of contribution. This check is to ensure that your names will appear correctly online and when the article is indexed.

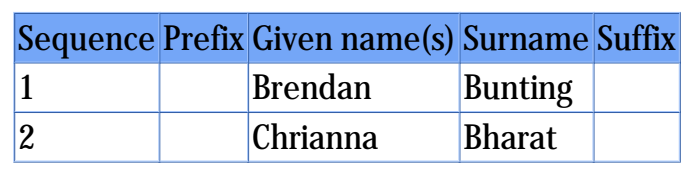

Response: Resolved

Query: AQ2: The reference "Johnson and Schultz, 2005" is cited in the text but is not listed in the references list. Please either delete the in-text citation or provide full reference details following journal style.

Response: Resolved

Query: AQ3: A disclosure statement reporting no conflict of interest has been inserted. Please correct if this is inaccurate.

Response: Resolved

Query: AQ4: Please provide missing author names for et al. for the "Heeringa et al. 2008" references list entry.

Response: Resolved

Query: AQ5: The reference "Johnson and Gerstein 2002" is listed in the references list but is not cited in the text. Please either cite the reference or remove it from the references list.

Response: Resolved

Query: AQ6: The reference "Kerr et al. 2009" is listed in the references list but is not cited in the text. Please either cite the reference or remove it from the references list.

Response: Resolved

Query: AQ7: Please provide missing author names for et al. for the "Keyes et al. 2011" references list entry.

Response: Resolved

Query: AQ8: The reference "Keyes et al. 2011" is listed in the references list but is not cited in the text. Please either cite the reference or remove it from the references list.

Response: Resolved

Query: AQ9: Please provide missing author names for et al. for the "Lee et al. 2009" references list entry. Response: Resolved

Query: AQ10: The reference "Loughrey and Curran 1987" is listed in the references list but is not cited in the text. Please either cite the reference or remove it from the references list.

Response: Resolved

Query: AQ11: Please provide missing et al. names and chapter title for the "Pennell et al. 2008" references list entry. Response: Resolved

Query: AQ12: Please provide missing author names for et al. for the "Rice et al. 2003" references list entry. Response: Resolved

Query: AQ13: Please provide missing page number for the "Slade et al. 2016" references list entry.

Response: Resolved

Query: AQ14: Please mention Table 1 in the text.

Response: Resolved

Query: AQ15: The funding information provided has been checked against the Open Funder Registry and we failed to find a match. Please check and resupply the funding details if necessary.

Response: Resolved 
Query: AQ16: The ORCID details of the authors have been validated against ORCID registry. please check the ORCID ID details of the authors.

Response: Resolved 